\section{TRÁFICO DE JÓVENES EN EL FÚTBOL: DIAMANTES NEGROS, UN TEXTO CINEMATOGRÁFICO DE SOCIOLOGÍA PÚBLICA}

\author{
YOUTH TRAFFICKING IN SOCCER: DIAMANTES NEGROS (BLACK DIAMONDS), \\ A CINEMATOGRAPHIC TEXT OF PUBLIC SOCIOLOGY
}

\author{
TRÁFICO DE JOVENS NO FUTEBOL: DIAMANTES NEGROS, UM TEXTO \\ CINEMATOGRÁFICO DE SOCIOLOGIA PÚBLICA
}

José-Ignacio Barbero-González*, Hugo Rodriguez-Campazas**

\section{Palabras clave}

Cine.

Fútbol.

Migración humana

Trata de Personas.

Sociología.
Keywords

Motion pictures.

Soccer.

Human migration.

Human trafficking.

Sociology.

Palavras-chave

Cinema.

Futebol.

Migração humana.

Tráfico de pessoas.

Sociologia.
Resumen: El propósito de este artículo es mostrar, sirviéndonos de la película "Diamantes Negros", el potencial del cine como medio, recurso o texto de sociología pública. La película escogida aborda el asunto del tráfico de niños (africanos) en el ámbito del fútbol. Su claridad expositiva, la relevancia del problema narrado y el compromiso emocional que genera nos impulsó a indagar en dicha problemática. Al repasar la literatura académico-científica, hemos constatado, entre otras cosas, primero, el carácter casi pionero en el contexto español de dicho texto fílmico y, segundo, grandes coincidencias discursivas entre los escritos académicos convencionales y la ficción cinematográfica. Teniendo en cuenta dichas similitudes y el contenido y características formales de la película, se defiende que Diamantes Negros es un buen texto de sociología pública.

Abstract: Drawing upon the movie Diamantes Negros (Black Diamonds), the purpose of this paper is to illustrate the potential of cinema as a resource, or text, of public sociology. The film deals with the issue of African child trafficking in soccer. The clarity of the story, the relevance of the problem addressed and the emotional involvement, moved us to inquire into such a problematic. Having considered the academic-scientific literature, we have confirmed, among other things, the following: a) the (almost) pioneering character of the filmic text within the Spanish context; and b) the discursive similarities among the academic texts and the cinematographic fiction. Taking into account these similarities and the content and formal features of the movie, it is argued that Diamantes Negros is a good example of a public sociology text.

Resumo: Este artigo tem como propósito mostrar, utilizando-nos do filme Diamantes Negros, o potencial do cinema como meio, recurso ou texto de sociologia pública. 0 filme escolhido aborda o tema do tráfico de meninos (africanos) no âmbito do futebol. Foi sua clareza expositiva, a relevância do problema narrado e o compromisso emocional que nos impulsionou a tratar tal problemática. Ao revisar a literatura acadêmico-cientifica, constatamos, entre outros, primeiro, o caráter quase pioneiro do dito texto fílmico no contexto espanhol e, segundo, grandes coincidências discursivas entre os escritos acadêmicos convencionais e a ficção cinematográfica. Considerando tais similitudes, 0 conteúdo e as características formais do filme, defendemos que Diamantes Negros é exemplo de um bom texto de sociologia pública.
* Departamento: Didáctica de la Expresión Musical, Plástica y Corporal. Facultad de Educación y Trabajo Social Universidad de Valladolid. Valladolid. España. E-mail: jigna@mpc.uva.es

** Departamento: Didáctica de la Expresión Musical, Plástica y Corporal. Facultad de Educación. Universidad de Valladolid. Segovia, España. E-mail: hugorc@mpc.uva.es

Recebido em: 30-06-2014 Aprovado em: 24-10-2014 (c) (1) (8) Licence 


\section{INTRODUCCIÓN}

El punto de partida de este artículo es la película del (sub)género deportivo Diamantes Negros (ALCANTUD, 2013), un drama de ficción hispano-portugués basado en hechos reales que pone sobre el tapete el asunto de la explotación y tráfico de jóvenes de color africanos que llevan a cabo una variopinta saga de ojeadores, agentes y cazatalentos europeos sin escrúpulos. En concreto, el relato narra las desventuras de dos malís menores de edad (Amadou y Mousa, 15 y 16 años respectivamente), ilegalmente introducidos en Europa con la promesa de fichar por un gran club de fútbol francés. Las condiciones de posibilidad del engaño son dos: el sustrato de pobreza de los protagonistas y el cultivado imaginario de escapar de ella mediante el deporte.

En nuestro acercamiento al cine deportivo, consideramos que las películas (Diamantes Negros, en este caso) son textos académicos no convencionales de gran utilidad como fuente primaria para la investigación y como recurso pedagógico para la enseñanza en el campo de las Ciencias de la Educación Física y el Deporte (BARBERO, 2011; BARBERO; RODRÍGUEZ, 2010, 2012, 2013). Este planteamiento no es original.

En primer lugar, las ciencias sociales hace tiempo que consideran que el cine (y otras formas de expresión más o menos artísticas) son textos culturales (DENZIN, 1989, p. 37) que hablan a la sociedad y la explican (reproduciendo, cuestionando, glorificando, etc.) sus problemas cotidianos. Incidir en el hecho de que una obra de arte es un texto cultural equivale, de algún modo, a su desacralización; parafraseando a Varela y Álvarez-Uría (2008, p. 163), a la eliminación del estatuto de extraterritorialidad social que a menudo se atribuye al arte.

En segundo lugar, durante las últimas tres décadas, se ha multiplicado la literatura que se ha apoyado en el cine para, desde la imaginación sociológica, indagar y explicar problemáticas diversas: educación, género, orientación sexual, raza, teoría social, violencia, globalización, identidad, etc. (véanse, por ejemplo, las obras colectivas de POULTON; RODERICK, 2008; SUTHERLAND; FELTEY, 2012). A dicha temática, cabría añadir el asunto que aquí nos ocupa, la emigración y el tráfico de personas en el ámbito deportivo (fútbol).

Finalmente y asociado a lo anterior, recientemente hemos asistido también a una proliferación discursiva en la investigación sobre las prácticas pedagógicas que gira en torno a la conveniencia (o no) de utilizar "textos no convencionales" o "textos no tradicionales", unas expresiones que agrupan, según los casos, a todo texto cultural situado extramuros de los habituales libros de texto o los artículos académico-científicos (CASTELLANO; DEANGELIS; CLARK-IBAÑEZ, 2008).

En este marco, pensamos que, por sus características formales (narración accesible y atrayente) y contenido (en relación al objeto de estudio, pionero en el contexto español), Diamantes Negros es un texto cultural no convencional de sociología pública.

\section{OBJETIVO}

El propósito de este artículo es ilustrar, basándonos en la película hispano-portuguesa Diamantes Negros (2013), el potencial del cine como medio, recurso o texto de sociología pública para explicar a la gran audiencia la explotación y el tráfico de jóvenes del llamado tercer mundo que tiene lugar en el ámbito del fútbol. 
Como el contexto social de referencia de la película escogida es África, nuestro relato -construido a partir del diálogo entre el texto fílmico y los textos científicos/académicos- se ha centrado en dicho continente. Sin embargo, es fácil imaginar lo arduo que resulta pensar en el movimiento y tráfico de jóvenes futbolistas sin que vengan a la cabeza las historias de muchos jugadores latinoamericanos. Por ello, sin ánimo de establecer paralelismos automáticos, en la última parte de este escrito nos apoyamos en la obra de un autor chileno (MENESES, 2013) para sugerir posibles extrapolaciones e incitar a la reflexión en dicho contexto.

\section{NOTAS TEÓRICAS}

La sociología pública es un movimiento intelectual que resurge a finales del siglo pasado cuestionando la razón de ser y el propósito de la disciplina y que cristaliza en los inicios del nuevo milenio (BURAWOY, 2005a; JEFFRIES, 2009).

Sin entrar, porque no es nuestro propósito, en los debates teóricos y otras disputas que la sociología pública ha generado en el campo (ver, por ejemplo, BURAWOY, 2009; FERNÁNDEZ, 2006), entre sus rasgos característicos destacamos, en relación con este escrito, los siguientes:

- La orientación popular, entendiendo aquí tal expresión como el deseo de que las explicaciones sociológicas sean comprensibles al común de los mortales. Al inicio de un texto autobiográfico en el que Burawoy explica la emergencia del proyecto, se pregunta: "Si la sociología no es «pública», entonces ¿qué demonios es?, ¿por qué molestarse en hacer sociología si ésta no tiene una misión pública?" (BURAWOY, 2013, p. 279).

- La necesidad de que el científico social público conecte, se comprometa e implique en la comunidad contribuyendo a la configuración y explicación de problemas relevantes para la sociedad civil. A este respecto, las tres grandes metas de la sociología pública son: colaborar con las comunidades oprimidas para incrementar su capacidad y poder; trabajar para transformar el sentido común ${ }^{2}$ con el que las personas se explican los problemas cotidianos (locales o privados) de su contexto inmediato y lograr que dichos asuntos pasen a formar parte del debate público; y defender la legitimidad del científico social activista en el campo profesional en que vive (BURAWOY, 2007, p. 132).

Teniendo en cuenta los vaivenes históricos de la sociología, entendemos que este rasgo desplaza y redirige la atención de la disciplina hacia el que fue su objeto inicial, la cuestión social, la cual, en los tiempos que corren, podría resumirse como "la distancia que media entre las constituciones democráticas y la realidad de una vida social marcada por grandes desigualdades económicas, sociales y políticas" (ÁLVAREZ-URÍA; VARELA, 2011, p. 16).

- El esfuerzo para llegar a y dialogar con audiencias situadas fuera de los límites de la propia disciplina mediante la publicación de textos "accesibles" en medios de comunicación más cotidianos que las prestigiosas (así consideradas) revistas de impacto, sólo leídas por un reducido número de colegas de profesión.

\footnotetext{
1 Muchas de las publicaciones de Burawoy están disponibles en http://burawoy.berkeley.edu/index.htm

2 Burawoy (2007, p. 130) tiene una visión gramsciana del sentido común: las explicaciones con las que los oprimidos narran su propia opresión contienen elementos positivos y negativos, análisis parcialmente certeros y equivocados. En este sentido, Burawoy entiende (2013, p. 297) que la sociología pública es la "elaboración" del sentido común, de una particular parte del sentido común, que podemos llamar el "buen sentido", compuesto de la imaginación sociológica que relaciona biografía e historia, que reconoce que la fuente de los males personales están condicionados por fuerzas sociales más amplias. Al mismo tiempo, el sociólogo público trata de eliminar la otra parte del sentido común, el "mal sentido" -los mitos del individualismo, las ideologías del éxito...
} 
¿Qué es hoy la "sociología pública"? Dicho del modo más simple, es llevar la sociología a públicos que están fuera de la universidad, para dialogar con ellos sobre los asuntos públicos que han sido estudiados por los sociólogos (BURAWOY, 2005b, p. 71).

Este diálogo, continúa el autor, tiene una triple dimensión: es un diálogo entre sociólogos; entre éstos y los públicos; y, el más importante, entre el propio público.

- Finalmente, el científico social público es un sociólogo público orgánico que mantiene una relación directa con un grupo o movimiento contribuyendo a contrarrestar el desequilibrio de fuerzas sociales.

En todo caso, el rol de "apóstol" o "predicador" de la sociología pública que asume Burawoy (2013, p. 279) no le lleva a considerar que las otras sociologías (profesional, crítica y aplicada/práctica ${ }^{3}$ ) deban desaparecer del mapa. Al contrario, a pesar del desigual reparto de poder y de las disputas dentro del campo, Burawoy defiende la necesidad de todas las formas de hacer sociología. Quizás, para terminar, quepa mencionar, dada su posible equiparación, la distinción entre las sociologías "crítica" y "pública". Para este autor (2013, p. 292), la primera dirige su reflexión hacia la propia disciplina y su público son los otros sociólogos y no el público extra-académico.

El cine, por su parte, documental o ficción, siempre transmite una visión particular del "trozo" de mundo que narra y, en tal sentido, incita con frecuencia a "reflexionar sobre lo imaginario de la realidad y la realidad de lo imaginario" (MORIN, 1977, prefacio añadido en la edición de 1982).

¿Cuál es el peso de la realidad y cuál el del imaginario en las vidas de los dos jóvenes diamantes negros?; ¿qué conflictos y dilemas provoca el relato fímico en el modo en que los espectadores imaginan la realidad narrada? En cuanto arte "total", así considerado por muchos, que conjuga imágenes en movimiento, lenguaje, música, fotografía, interpretación, etc., el cine invita al espectador a identificarse con los protagonistas del relato y permite la experiencia (virtual) vivenciada de sus esperanzas, alegrías y fracasos.

Además, el cine, en cuanto arte y en cuanto ficción, goza de una libertad que le permite curiosear y avanzar por caminos inexplorados por la ciencia y los escritos académicos tradicionales. A este respecto, no creemos exagerado afirmar que Diamantes Negros es uno de los primeros textos de autoría española que aborda el asunto del tráfico de personas con motivo del fútbol. La trama de la novela juvenil "Un balón por una bala" (SALMERÓN, 2012), también una obra de ficción, nos traslada igualmente a África, Sierra Leona, donde un diamante negro recién retirado de la liga inglesa quiere montar una academia de fútbol con el fin de recuperar a los niños que han sobrevivido a las cruentas guerras tribales. Esta problemática también ha sido objeto de reportajes de prensa y televisión (como botón de muestra, ÉVOLE, 2014, incluye una entrevista con Alassane Diakité, uno de los diamantes de la película, jugador de un equipo de barrio de Madrid). En general, el sesgo de las investigaciones realizadas en España es el de la integración mediante el deporte de los emigrantes ya residentes (DOMÍNGUEZ, 2009 4; DOMÍNGUEZ, JIMÉNEZ; DURÁN, 2010). En los países hispanohablantes de América Latina tampoco abundan los estudios

3 La expresión "Policy sociology" (sociología al servicio o dependiente de instituciones públicas o privadas) aparece traducida, según los casos, como "sociología aplicada" o como "sociología práctica".

4 DOMíNGUEZ, Sara. Deporte e inmigración: el deporte como elemento de aculturación de los ecuatorianos en la ciudad de Madrid, Tesis (Doctoral), no publicada, 2009, Madrid: Universidad Politécnica, 2009. 
sobre este tema y su enfoque suele ser bastante general (STEFFANO, 2012); caso distinto es la mencionada obra "Niños futbolistas" (MENESES, 2013), un relato periodístico-novelado basado en la experiencia del autor, quien, para investigar el asunto, se dedicó varios meses a la búsqueda y compra de un niño con el propósito de venderlo en Europa, en concreto, en España.

En esta tesitura, como se ha dicho, dada la relevancia del problema y las características formales del relato, Diamantes Negros nos parece un buen texto "no convencional" de sociología pública.

\section{NOTAS METODOLÓGICAS}

\subsection{Muestra. La elección de Diamantes negros}

Tras el rastreo pertinente por las distintas bases de datos de películas que abordan el asunto de la emigración y del tráfico de jóvenes por razones deportivas, escogimos finalmente este texto por tres motivos que remiten a las características de la sociología pública: i) en cuanto ficción cinematográfica, el mensaje es accesible y atrayente para la audiencia no especializada; ii) quizá -aunque no necesariamente- al estar basada en hechos reales, la narración explica y permite captar mejor el contexto socio-económico-cultural de la explotación y el tráfico de menores que tiene lugar bajo el paraguas del fútbol; en otras palabras, invita al espectador a establecer conexiones entre las vidas de las personas, la sociedad y la historia; y iii) el hecho de ser uno de los primeros textos que, en el contexto español, aborda dicho asunto.

\subsection{Análisis de contenido}

Tras la selección de la película, los dos autores hemos realizado por separado el primer análisis de su contenido en el que, dadas las características del texto fílmico, procuramos prestar atención a sus distintos elementos: lenguaje visual, sistemas verbales, diálogo, caracterización, etc. El propósito en esta primera etapa era identificar los distintos temas, categorías 0 "conceptos-imágenes" (CABRERA, 2008, p. 17-32), vocablos que utilizamos como sinónimos, que emergen en el relato. A continuación, segundo momento, pusimos en común los datos particulares, contrastamos acuerdos y divergencias y elaboramos un esquema provisional de categorías, subcategorías y cuestiones sin resolver. Posteriormente, tercer momento, volvimos a ver por separado la película; ahora, dicho guión provisional orientó nuestra mirada. En un cuarto momento, volvimos a poner los datos en común y a planificar la redacción de este texto.

Finalmente, quinto momento, la propia escritura, que nosotros entendemos como un proceso de escrituras sucias ubicado dentro (no después) de la investigación, caracterizado por altibajos y pasos hacia adelante y hacia atrás, una suciedad que normalmente es ocultada por la relativa claridad y coherencia del producto final que se ofrece al lector. (ALTHEIDE, 1987; DENZIN, 1989, 2004; RICHARDSON, 2000; NEUENDORF, 2002; BARDIN, 2002; KRIPPENDORFF, 2004).

\section{TRÁFICO DE SERES HUMANOS}

Para facilitar la comprensión de este breve informe-relato, lo hemos estructurado en cuatro grandes apartados que responden a un cierto orden cronológico. En primer lugar, plan- 
teamos lo que hemos denominado "Las condiciones de posibilidad de la extracción de los diamantes: globalización y pobreza", es decir, el punto de partida o prerrequisito del mercadeo de niños futbolistas; a continuación, bajo el subtítulo "Tráfico de personas a coste cero", destacamos el nulo riesgo con el que afrontan su trabajo los traficantes; en tercer lugar, centramos la atención en algunas de las claves del "circuito de la explotación/emigración"; finalmente, el interrogante "¿Éxito al final del viaje?” propone una reflexión sobre la conclusión del trayecto que, con gran ilusión, iniciaron los niños futbolistas: dadas las circunstancias (piénsese, por ejemplo, en la presente crisis del virus Ébola), nos preguntamos si permanecer en el primer mundo, aunque sea vagabundeando por las calles, no constituye, desgraciadamente, el verdadero triunfo.

\subsection{Las condiciones de posibilidad de la extracción de los diamantes: globalización y pobreza}

Esta categoría aglutina un conjunto de interrogantes relativos a las causas y naturalidad de la explotación. Los subtemas explicativos que emergen en la película son: el estado de pobreza de los protagonistas y de su entorno; la configuración del fútbol como un medio real para escapar de ella y ayudar a la familia; y el peso de los campeones (Lampard, Ballack, Keita, Weah, Messi...) en el imaginario individual, familiar y colectivo.

Este concepto-imagen emerge al inicio de la película: las primeras escenas de Diamantes Negros nos muestran a niños y jóvenes con camisetas descoloridas de distintos equipos europeos jugando al fútbol en campos de tierra con porterías destartaladas situados al lado de una escombrera. El punto de partida es, pues, la pobreza y el fútbol; aquélla resume las condiciones materiales de existencia, éste refleja su influencia y carácter central en la cultura global.

El vocablo "globalización", apenas utilizado hace cuarenta años (GIDDENS, 2003, p. 20), se ha convertido hoy en una polisémica expresión comodín con la que se alude a los flujos e interdependencias económicas, tecnológicas, etc. a escala planetaria ("mondialisation" en francés) y a una creciente homogeneización cultural.

En contra de lo que tendemos a pensar, los procesos de globalización son más antiguos de lo que parecen, no responden a una única lógica y tampoco son neutrales (los estados pierden autonomía, determinados actores transnacionales imponen sus intereses y, en fin, la homogeneización cultural no es producto de eclecticismos simétricos):

En términos culturales, el nuevo tipo de globalización tiene que ver con una nueva forma de cultura de masas global, muy diferente de [...] las identidades culturales asociadas a la nación-estado de una fase anterior. La cultura de masas global está dominada por los modernos medios de producción cultural, por la imagen que cruza y cruza fronteras lingüísticas rápida y fácilmente, y que habla... de un modo mucho más inmediato. [...] Está dominada por la televisión y el cine, y por la imagen, imaginería, y la publicidad de masas. Su epítome es todas esas formas de comunicación de masas de las que uno puede pensar que la televisión vía satélite es el primer ejemplo. No porque sea el único ejemplo sino porque no podríamos entender la televisión vía satélite sin entender su anclaje en una particular y avanzada economía y cultura nacional y eso a pesar de que su propósito es precisamente que no puede por más tiempo estar limitada por fronteras nacionales (HALL, 2000, p. 27).

En este sentido, por hechos hoy considerados habituales (retransmisión en directo, audiencia transcontinental, aplicación de nuevas tecnologías de tratamiento de la imagen...), el 
Mundial de 1966 celebrado en Inglaterra contribuyó significativamente al proceso de mundialización del fútbol (CHISARI, 2006). Naturalmente, si miramos hacia atrás, se pueden enumerar otros muchos eslabones igualmente importantes. Sirva como botón de muestra, tanto en lo artístico como en lo tecnológico, las casi cuatro horas de "Olympia" (REIFENSTAHL, 1938) con motivo de los Juegos Olímpicos de 1936 en Berlín.

Por otra parte, en cuanto elemento central de la globalización, el fútbol se ha convertido en un producto que se distribuye y consume en todo el mundo produciendo una "homogeneización cultural" equivalente a la "Cocacolalización" o "McDonaldlización" (DEJONGHE, 2001, p. 81) y, en tal sentido, opera como una instancia de imperialismo cultural (SCHILLER, 1976). Apoyándonos en el cine, la trama de "La Gran Final" (OLIVARES, 2006) ilustra dichas dimensiones (homogeneización y globalización cultural) del deporte rey: la obsesión de tres grupos de personas de contextos socio-culturales muy dispares por ver la final del Mundial de 2002 entre Alemania y Brasil.

Por otra parte, la globalización del libre mercado, de los flujos financieros y tecnológicos o de la llamada nueva economía no ha resuelto el problema de la pobreza sino que, en buena medida, enmascara nuevas formas de neo-colonialismo. En este sentido, si la difusión global e instantánea del fútbol a través de las distintas pantallas y el éxito de las estrellas deportivas configuran la imaginería de la redención mediante el fútbol (la llamada del "sueño de ser Messi"), la pobreza empuja a escapar y a "saltar la valla de Melilla (frontera española en el norte africano) cueste lo que cueste", explica Issouf Sanfo, un joven futbolista de Burkina Faso que declara haber "visto en internet cómo se vive en Europa" (ROJAS, 2014), y que bien podría protagonizar otro relato de Diamantes Negros.

\subsection{Tráfico de personas a coste cero}

Esta categoría fija la atención en el nulo riesgo que asumen las personas que trafican con los futbolistas. Ateniéndonos al análisis de contenido de la película, los subtemas que lo desglosan son: los jóvenes ya saben jugar, han aprendido por su cuenta y en las "academias"; todos los gastos iniciales de falsificación de "papeles" (edad, pasaporte, propósito del viaje...) y billetes son asumidos por las familias que apoyan sin reservas el proyecto; los menores son tratados como meras mercancías que se cogen, transportan, manipulan y, si no sirven, se abandonan como material de desecho; el papel de las academias, habitualmente de pago, reforzando el sueño de la redención mediante el fútbol; y los ojeadores que escogen a los jóvenes deportistas en función del potencial que les atribuyen, como si fuesen diamantes en bruto que, tras ser pulidos, multiplicarán su precio en el mercado.

Entre los numerosos fragmentos de la película que desarrollan este concepto-imagen escogemos aquel que muestra las estrategias de financiación (3.000 euros) de las dos familias (17'-20'). Una, un poco más acomodada, organiza una fiesta en su aldea durante la cual los convecinos realizan pequeñas aportaciones; la otra, mucho más pobre, acaba vendiendo el hijo menor a un comerciante de la ciudad.

Si nos atenemos al artículo 3 del "Protocolo para Prevenir, Reprimir y Sancionar la Trata de Personas..." (ONU, 2001), la extracción-apropiación-traslado-y-mercadeo de los Diamantes Negros es, sin lugar a dudas, tráfico de niños. 
Como se ha explicado, la pobreza, la fragilidad económica de los países de origen y el imaginario de un porvenir dichoso en el primer mundo gracias al deporte coadyuvan a configurar una oferta de la que se aprovechan los traficantes. En este contexto, durante las últimas tres décadas han proliferado en África las academias, unas instituciones que actúan como dispositivos que fomentan la exportación de talentos y recrean el imaginario de la salvación mediante el fútbol.

La literatura (ALEGI, 2010, DARBY; AKINDES; KIRWIN, 2007; DARBY, 2012) distingue cuatro tipos de academias: las tuteladas por clubes y organismos públicos o privados africanos, las dependientes de proyectos conjuntos entre clubes europeos y africanos, las fundadas por un patrocinador privado (e.g., una marca comercial o una estrella futbolística en activo o retirada) y, finalmente, las más numerosas, las ad hoc, instituciones privadas que

[...] exponen a los jóvenes africanos a la avaricia de agentes no certificados que los reclutan a bajo precio y convencen para que, caso de que triunfen en las pruebas, firmen contratos explotadores (DARBY, AKINDES \& KIRWIN, 2007, p. 153).

La proliferación de todas estas instituciones -donde las ad hoc distan mucho del modelo ideal que combinaría la formación académica y futbolística- se debe a que, a través de ellas, es más fácil sortear la reciente normativa restrictiva de la emigración. De un modo u otro, casi todas ellas operan como plantaciones destinadas a producir cosechas cuyo fin último son los clubes ricos de las ligas europeas, lo que Hayatou, presidente de la Confederación Africana de Fútbol, calificó como "éxodo de músculo" que, a su vez, refuerza la dependencia y pobreza económico-deportiva de los clubes y ligas africanas. A este respecto, valga como ilustración que el $89,4 \%$ de los jugadores africanos del mundial de Brasil-2014 juega en ligas europeas y, de él, el $52,1 \%$ en las ligas inglesa, italiana, francesa, alemana y española, las más importantes (ALEGI, 2014).

\subsection{El circuito de la explotación/emigración}

Esta categoría evoca los distintos momentos y agentes de un recorrido que comienza cuando un ojeador propone a los niños lo que ellos más añoran, ir a Europa. Los subtemas que la componen son: el visitante que recolecta los diamantes en bruto diciéndoles que van a acabar jugando en un gran club y viviendo en alguna de sus residencias; el deslumbrante atractivo (luces, coches, publicidad...) del primer mundo; la falta de escrúpulos de los europeos (intermediarios diversos, entrenadores o jugadores) que intervienen en el proceso; la separación de los protagonistas -que impide el apoyo mutuo-; los inevitables momentos de relativa degradación humana que acontecen cuando Amadou y Moussa, abandonados en un mundo desconocido, uno en Lisboa y el otro en Madrid, se ven obligados a delinquir por mera supervivencia.

Como síntesis de este concepto-imagen escogemos el fragmento en el que, tras ser detenido en Madrid, la policía, siguiendo su protocolo de actuación, obliga a Moussa a desnudarse mientras éste suplica “iPor favor, no!, ipor favor, no!, ¡Dios, por favor!...”; paralelamente, Amadou pide ayuda en una comisaría lisboeta y se la niegan (78'-82').

Según la neutra definición de la OIM (2007), un emigrante es una persona que decide libremente trasladarse a otro lugar, solo o con su familia, con el fin de mejorar sus condiciones materiales y/o sociales. Ciertamente, en el mundo del deporte existe una emigración cualificada 
(por ejemplo, de técnicos, directivos o deportistas) que responde a dicho modelo; sin embargo, también hay otra más numerosa, como la de nuestros jóvenes diamantes negros, que se nutre de engaños, promesas falsas, contratos ilegales... En este sentido, el problema que plantea el relato cinematográfico puede encuadrarse en el marco general de las migraciones deportivas.

Aunque la emigración en el fútbol no es nueva y, de hecho, el desarrollo y difusión del propio deporte no hubiera sido posible sin la movilidad territorial de sus apóstoles y jugadores, el interés académico por este asunto es bastante reciente (BALE; MAGUIRE, 1994; LANFRANCHI; TAYLOR, 2001; TAYLOR, 2006; POLI, 2007, 2008; DARBY, 2007, 2011).

La explicación clásica más tradicional tiende a privilegiar el papel de las condiciones económicas como fuerza que empuja a abandonar las zonas periféricas de pobreza hacia los países ricos de destino, por ejemplo, desde África, Latinoamérica y el este europeo hacia el oeste de Europa.

Sin menospreciar la influencia de lo económico, muchos de los autores mencionados (por ejemplo, TAYLOR, 2006, p. 16-19) consideran dicho factor insuficiente y proponen modelos "relacionales" que prestan además atención al papel de la cultura (lengua, religión...), la historia (lazos coloniales, emigraciones precedentes, acuerdos de doble nacionalidad, conexiones económicas...) y las instituciones (regulaciones federativas que prohíben, restringen o amplían el número de jugadores foráneos, la ley Bosman de 1995, etc.) en la configuración de los canales migratorios. Desde esta óptica, las razones económicas (escapar de la pobreza), siendo el factor más importante, no explican por sí solas el modo en que la emigración es socialmente construida en contextos socio-históricos concretos. La pobreza, per se, es insuficiente para comprender por qué los emigrantes angoleños y mozambiqueños se han concentrado tradicionalmente en Portugal, o los latinoamericanos en Italia y España, o los africanos en Bélgica y Francia 0 , en fin, por qué muchos futbolistas instalados en los países ricos del centro y norte europeo se trasladan a las ligas del sur del continente. Éste es, quizás, el marco en el que nuestros dos diamantes negros malís (idioma francés, excolonia francesa, estrellas emigrantes en Francia...) añoran ir, aunque les valga cualquier otro equipo y lugar, al París Saint-Germain.

Este enfoque permite detectar la configuración y transformación de las redes migratorias (deportivas) a lo largo del tiempo, pone de manifiesto la inexistencia de un mercado único laboral global y, en consecuencia, problematiza ciertas visiones naíf de la globalización.

\section{4 ¿Éxito al final del viaje?}

Esta categoría fija su atención en la última etapa de las trayectorias separadas de los dos diamantes. Los subtemas aquí incluidos son: el significado y consecuencias del retorno (¿fracaso individual?, ¿deshonor individual y familiar?, deudas contraídas, etc.), las estrategias para, ante todo, permanecer en Europa y, en última instancia, no verse obligado a volver.

Para ilustrar este concepto-imagen escogemos el fragmento (86'-94') en el que Amadou, abandonado en Portugal con el ligamento cruzado de su rodilla derecha destrozado, vuelve a su aldea y descubre cómo se pagó su viaje (el destino de su hermano menor); mientras tanto, Moussa termina a orillas del Báltico, de comparsa de otra joven estrella cedida por un gran club europeo, también menor de edad, quien, para ser feliz, progresar en su juego e incrementar su valor cambio, necesita compañeros de su país de origen. 
Antes de la habitual lista de créditos, Diamantes Negros concluye con el siguiente mensaje:

En las calles de Europa sobreviven unos 20.000 jóvenes africanos traídos por agentes persiguiendo su sueño de jugar al fútbol.

Un dato elocuente que se queda quizás corto al calificar como "jóvenes" a dichos supervivientes. El encabezamiento del reportaje titulado "Dentro de las fábricas del fútbol que alimenta el bello juego" dice así:

Chicos de tan sólo 9 años están siendo explotados por hombres de negocios que confían en obtener beneficios vendiéndolos a clubes europeos (MCDOUGALL, 2007).

En la misma línea, referido ahora al fútbol latinoamericano, el periodista chileno Meneses explica el progresivo descenso de la edad de detección y contratación de talentos, llegándose al extremo de fichar a bebés. A este respecto, el bulo o chiste de la contratación, antes de nacer, del hijo de Agüero, que estuvo casado con una hija de Maradona, motivada por el talento genético atribuido, puede hacernos sonreír, pero es una metáfora de la lógica que subyace y orienta la actuación de muchos agentes e instituciones deportivas (MENESES, 2013, p. $145-154)^{5}$.

Respecto a la cifra (20.000), es una estimación que seguramente se queda corta, sobre todo si consideramos también los de procedencia no africana. Como ilustración, la Comisión de Infancia del Senado italiano concluyó que, en el año 2000, había en ese país 5.282 jugadores menores de 16 años, principalmente de origen africano, de los que sólo 23 tenían un contrato registrado; "la mayoría de ellos habían sido llevados a Italia de forma ilegal" (SAVE THE CHILDREN, 2008, p. 22).

Como se explica en este documento (SAVE THE CHILDREN, 2008, p. 16), la vergüenza del fracaso empuja a no regresar y, cuando los jóvenes telefonean a sus familiares, les mienten (como hace Moussa en la película) contándoles que todo les va muy bien, que los entrenamientos son fantásticos o que la residencia del club es muy acogedora.

Como es obvio, de acuerdo con la lógica del citius, altius, fortius de la pirámide deportiva (explicada sobradamente por la literatura especializada), sólo un puñado de los integrantes de la base alcanzan la cima y sólo un pequeño porcentaje de los que dedicaron miles de horas en su infancia y juventud consigue ganarse la vida por medio del fútbol.

¿Cuántos niños triunfan y cuántos fracasan?

Nadie triunfa. Messi es el gran culpable de lo que está pasando y él es un gran error estadístico. Su economía ahora es tan buena que la gente piensa que se trata sólo de sacar un niño de un barrio pobre, llevarlo a Europa y volverse millonario.

El fútbol es la telenovela de los hombres y en ese sentido siempre cuentan los finales felices: Messi, Falcao, Neymar. Nunca cuentan los que no tienen final feliz porque dejaría de ser telenovela (PAZ, 2013).

En esta tesitura, el verdadero éxito final del viaje para la mayoría de los diamantes negros consiste simplemente en permanecer en el primer mundo.

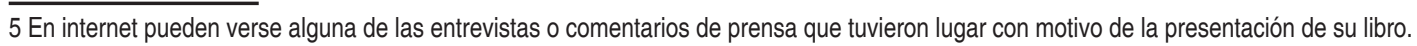




\section{CONCLUSIONES}

El propósito de este escrito era mostrar el potencial de una ficción cinematográfica, Diamantes Negros, como texto de sociología pública. A las razones mencionadas al principio, queremos añadir otras que atañen al proceso de indagación que dicha película ha activado en nosotros, los autores de este escrito.

La emigración y el tráfico de niños en el mundo del deporte (fútbol) no figuran entre nuestras líneas de interés académico y, por ello, nuestro seguimiento de tal problemática se limitaba a poco más que la lectura de las noticias de prensa. En esta tesitura, Diamantes Negros, además de proporcionarnos una explicación global del asunto, estimuló y canalizó nuestra curiosidad hacia la literatura especializada. En el proceso de lecturas subsiguiente hemos comprobado, como también nos ocurrió en trabajos anteriores, que las ficciones cinematográficas aportan explicaciones tan válidas como las de los textos científicos convencionales. En este caso, el discurso que predomina en estos últimos no contradice la narración de la ficción. Una diferencia muy significativa, sin embargo, es que ésta última opera con unos códigos que aquéllos tienden a menospreciar (por ejemplo, la implicación emocional del lector-espectador).

La explotación y tráfico de niños en el ámbito del fútbol saca a la luz el lado más oscuro y oculto de la omnipresente globalización. Frente a la idea de interdependencias mundiales equidistantes y de intercambios o movimientos de capital, tecnología e información en un mercado libre, abierto y beneficioso para todos, la explotación y el tráfico de diamantes negros nos planta los pies en la tierra y nos hace ver el abismo que separa a ricos y pobres, así como el modo en que, en el desierto de la pobreza, la homogeneizadora globalización cultural genera el espejismo de la redención mediante el fútbol en el imaginario de los hambrientos. Mientras que la tecnología, los capitales y la información se desplazan por la aldea global casi a su antojo, los pobres sólo pueden salir de su lugar de origen si, convertidos en mera mercancía, otros deciden traficar con ellos.

Diamantes Negros ha dirigido nuestra atención hacia la emigración y el tráfico de personas de origen africano en el mundo del fútbol. ¿Son los argumentos aquí utilizados transferibles a otros contextos sociales, por ejemplo, a América Latina? Veamos el primer párrafo del libro "Niños Futbolistas":

Hace pocas semanas cumplió once años y cree que el fútbol puede sacarlo de la pobreza. Lo dice muy seguro. Piensa que una carrera de futbolista, con triunfos y goles y aviones y giras y copas y contratos y anuncios publicitarios y hoteles y autógrafos, va a alejarlo de aquí, de esta cancha de tierra en una ciudad de América Latina, de este barrio donde es un peligro andar solo de noche y la droga corre más veloz que las ratas. Cree que si juega bien y trabaja duro podrá conocer mundo, por eso entrena mucho más de lo que estudia. Y sueña con llegar a fichar por algún equipo de Europa. Se imagina en lo más alto, vistiendo la camiseta del Barcelona o el Real Madrid o el Inter o la Juventus. No descarta Inglaterra, tampoco la Bundesliga... (MENESES, 2013, p. 7).

Un inicio que coincide con las primeras imágenes de Diamantes Negros: niños y jóvenes con camisetas descoloridas de equipos europeos jugando en campos de tierra con porterías destartaladas situados al lado de una escombrera... Ambas escenas se tejen con los mismos mimbres, la pobreza y el imaginario de la redención mediante el fútbol. 
Para terminar, retomando el objetivo de este escrito: ¿ilustra Diamantes Negros el potencial del cine como medio, recurso o texto no convencional de sociología pública? Dejamos al lector que considere si el problema que aborda esta película (u otras) es socialmente relevante; si contribuye a trasladar a la palestra pública un asunto tan habitual como dado por supuesto; si facilita la comprensión de las relaciones entre problemas concretos y las macro-fuerzas económicas, políticas y culturales; y si, al ver la película, le parece un texto accesible cuya lectura no requiere un dominio especial del arte. Diamantes Negros propone un análisis subversivo de la ideología que recrean otras muchas películas que, al narrar la misma realidad, glorifican "el sueño de ser Messi”; por ello, desde nuestra posición de docentes en el ámbito de la Educación Física y el Deporte, consideramos que este texto no convencional tiene un gran potencial para estimular la imaginación sociológica de nuestro alumnado.

\section{REFERENCIAS}

ALCANTUD, Miguel (Ed.). Diamantes negros, Madrid: Fado Filmes / Potenza Producciones, 2013. ALEGI, Peter. African Soccerscapes. How a continente changed the world's game, Ohio: Ohio University, 2010.

ALEGI, Peter. How Africa developed Europe. Football is coming Home, 23 may 2014. Disponível em: http://www.footballiscominghome.info/tag/migration/. Acesso em: 30 maio 2014.

ALTHEIDE, David L. Ethnographic Content Analysis. Qualitative Sociology, New York, v. 10, n.1, p. 65-77, 1987.

ÁLVAREZ-URÍA, Fernando; VARELA, Julia. Sociología, capitalismo y democracia, Madrid: Morata, 2011.

BALE, John; MAGUIRE, Joseph A. The Global Sports Arena: Athletic Talent Migration in an Interdependent World, Frank Cass, 1994.

BARBERO, José-Ignacio. Ficciones en torno al deporte en tiempos de crisis. Cultura, Ciencia y Deporte, Murcia, v. 6, n. 16, p. 65-71, 2011.

BARBERO, José-Ignacio; RODRÍGUEZ, Hugo. Significados y funciones del deporte en la vida "colegial". Análisis de tres películas de cine mudo. Ágora para la Educación Física y el Deporte, Valladolid, v. 12, n. 1, p. 49-74, 2010.

BARBERO, José-Ignacio; RODRÍGUEZ, Hugo. El deporte a principios del siglo XX: su (re)presentación en películas de distintas épocas. Cultura y Educación, Barcelona, v. 24, n 3, p. 305-318, 2012.

BARBERO, José-Ignacio; RODRÍGUEZ, Hugo. The near future in "rollerball" dystopian movie: fictional generative themes to stimulate sociological imagination within Physical Education and sports studies. Movimento, Porto Alegre, v. 19, n. 3, p. 79-101, 2013.

BARDIN, Laurence. Análisis de contenido. Madrid: Akal, 2002.

BURAWOY, Michael. Por una sociología pública. Política y sociedad, Madrid, v.42, n. 1, p. 197-225, 2005a.

BURAWOY, Michael. The return of the repressed: recovering the public face of US Sociology, one hundred years on. The Annals of the American Academy of political and social science, Philadelphia, v.600, n. 1, p. 68-85, 2005b.

BURAWOY, Michael. Private troubles and public issues. En BARLOW, A.L. (ed.). Collaborations for social justice: professionals, public and policy change, Lanham-Maryland: Rowman \& Littlefield, 2007. p. 125-134, 
BURAWOY, Michael. The public sociology wars. En JEFFRIES, V. (ed). Handbook of public sociology, Lanham-Maryland: Rowman \& Littlefield, 2009.p. 449-473.

BURAWOY, Michael. Public sociology: the task and the promise. En: GOULD, K.; LEWIS, T. (Eds.). Ten lessons in introductory sociology, Oxford: Oxford University, p. 279-298, 2013.

CABRERA, Julio. Cine: 100 años de filosofía. Barcelona: Gedisa, 2008.

CASTELLANO, Ursula; DE ANGELIS, Joseph; CLARK-IBÁÑEZ, Marisol. Cultivating a sociological perspective using nontraditional texts. Teaching Sociology, Washington, v. 36, n. 3, 240-253, jul. 2008.

CHISARI, Fabio. When football went global: Televising the 1966 World Cup. Historical Social Research, Colonia, v. 31, n.1, p. 42-54, 2006.

DARBY, Paul. Migração para Portugal de jogadores de futebol africanos: recurso colonial e neocolonial. Análise Social, Lisboa, v. 41, n. 179, p. 417-433, 2006.

DARBY, Paul. Out of Africa: The exodus of elite African football talent to Europe. Working USA, v.10, n. 4, p. 443-456, nov. 2007.

DARBY, Paul. Sport and migration: borders, boundaries and crossings. In: MAGUIRE, J.; FALCOUS, M. Sport and Migration: Borders, Boundaries and Crossings, London: Routledge, 2011. p. 245-258.

DARBY, Paul. Gains versus drains: Football academies and the export of highly skilled football labor. The Brown Journal of World Affairs, Providence, v. 43, n.2, p. 265-277, 2012.

DARBY, Paul; AKINDES, Gerard; KIRWIN, Matthew. Football Academies and the Migration of African Football Labor to Europe Journal of Sport \& Social Issues, London, v.31, p. 143-161, may 2007.

DEJONGHE, Trudo. The place of sub-Sahara Africa in the worldsportsystem. Afrika Focus, GentBelgium, v. 17, n. 1, p. 79-111, 2001.

DENZIN, Norman K. Reading Tender Mercies: Two Interpretations. The Sociological Quarterly, lowa, v.30, n. 1, p. 37-57, 1989.

DENZIN, Norman K. Reading film: using films and videos as empirical social science material. In: FLICK, U.; KARDORFF, E.V.; STEINKE, I. (Eds). A Companion to Qualitative Research. London: Sage. 2004. p. 237-242.

DOMÍNGUEZ, Sara; JIMÉNEZ, Pedro; DURÁN, Javier. Hábitos deportivos de la población ecuatoriana en la ciudad de Madrid. Análisis de su influencia en el proceso de integración en la sociedad española. Ágora para la Educación Física y el Deporte, Valladolid, v. 12, n. 3, p. 237-256, 2010.

ÉVOLE, Jordi. El fútbol también es así. In: Salvados, España: La Sexta TV, 04 mayo 2014.

FERNÁNDEZ, Manuel. El resurgimiento de la sociología pública. Revista Española de Sociología, Madrid, n. 6, p. 7-33, 2006.

GIDDENS, Anthony. Un mundo desbocado. Los efectos de la globalización en nuestros días. Madrid: Taurus, 2003.

HALL, Stuart. The Local and the Global: Globalization and Ethnicity. In: Anthony D. King (Ed.), Culture, Globalization and the World-System: Contemporary Conditions for the Representation of Identity. Minneapolis: University of Minnesota, 2000. p. 19-39.

JEFFRIES, Vincent. (ed.). Handbook of public sociology. Lanham-Maryland: Rowman \& Littlefield, 2009. KRIPPENDORFF, Klaus. Content analysis. An introduction to its methodology. Thousand Oaks: Sage, 2004.

KUPER, Simon; SZYMANSKI, Stefan. Soccernomics. New York: Nation Books, 2009.

LANFRANCHI, Pierre; TAYLOR, Matthew. Moving with the ball: the migration of professional footballers. Oxford: Berg, 2001. 
MCDOUGALL, Dan. Inside the football factories that feed the beautiful game. The Observer, 10 jun. 2007. Disponível em: http://www.theguardian.com/world/2007/jun/10/football.theobserver. Acesso em: 12 feb.2014.

MENESES, Juan-Pablo. Niños futbolistas, Barcelona: Blackie Books, 2013.

MORIN, Edgar. Le cinéma ou l'homme imaginaire. Paris: Minuit, 1977. (Un largo extracto del Prefacio añadido en 1982 puede verse en: http://simpleappareil.free.fr/lobservatoire/index. php?2009/10/02/65-la-realite-semi-imaginaire-de-l-homme). Acesso em: 15 ene.2014.

NEUENDORF, Kimberly A. The Content Analysis Guidebook. Thousand Oaks: Sage, 2002.

OLIVARES, Gerardo de (Dir.) La gran final. España: Wanda Films, 2006.

ONU. PROTOCOLO para prevenir, reprimir y sancionar la trata de personas, especialmente mujeres y niños, que complementa la Convención de las Naciones Unidas contra la Delincuencia Organizada Transnacional. Resolución aprobada por la Asamblea General de la Naciones Unidas: 55/25 de 2001. Disponible em: http:/www.unodc.org/documents/treaties/UNTOC/ Publications/TOC\%20Convention/TOCebook-s.pdf. Acesso em: 21 dec.2013.

PAZ, Antonio. Entrevista a Juan Pablo Meneses. Semana.com, Bogotá, 28 nov. 2013. Disponível em: http://www.semana.com/vida-moderna/articulo/compra-venta-de-ninos-en-el-futbol/366354-3. Acesso em: 15 dec.2013.

POLI, Raffaele. Migrations et commerce de footballeurs africains: aspects historiques, géographiques et culturels. We pare football, Draguignan, p. 1-12, 2008. Disponível em: http://www.wearefootball. org/PDF/une-nouvelle-traite.pdf. Acesso em: 25 ene.2014.

POLI, Raffaele. Migrations de footballeurs et mondialisation: du système-monde aux réseaux sociaux. M@ppemonde, Montpellier, v. 88, n. 4, p., 1-12, 2007. Disponível em: http://mappemonde.mgm.frl num16/articles/art07401.html. Acesso em: 25 ene.2014.

POULTON, Emma; RODERICK, Martin (eds.). Sport in films, London: Routledge, 2008.

RICHARDSON, Laurel. Writing. A method of inquiry. In: DENZIN, N.K.; LINCOLN, Y.S. (Eds.)

Handbook of qualitative research. Thousand Oaks: Sage, 2000. p. 923-948.

REIFENSTAHL, Leni. (Dir.) Olympia. Alemania: Olympia Film / Tobis Filmkunst, 1938.

ROJAS, Alberto. El zoo del siglo XXI/Issouf Sanfo, El Mundo, Madrid, p. 76, 18 mayo 2014.

SCHILLER, Herbert I. Communications and cultural domination, Nueva York: Sharpe, 1976.

SALMERÓN, Rafael. Un balón por una bala, Madrid: SM, 2012

SAVE THE CHILDREN. Niños en competición. Madrid: S.T.Ch., 2008. Disponível em: http://www. oei.es/pdfs/Ninos competicion.pdf. Acesso em: 15 dec.2013.

STEFFANO, Dante, W. Deporte y migración: aportes para su comprensión desde el caso uruguayo. Revista da ALESDE, Curitiba, v.2, n.2, p. 33-43, 2012.

SUTHERLAND, Jean-Anne; FELTEY, Kathryn M. (eds.). Cinematic Sociology. Social Life in Film, London: Sage, 2012.

TAYLOR, Matthew. Global players? Football, migration and globalization, c. 1930-2000. Historical Social Research, Colonia, v. 31, n.1, p. 7-30, 2006.

VARELA, Julia; ÁLVAREZ-URÍA, Fernando. Materiales de sociología del arte. Madrid: Siglo XXI, 2008. 